\title{
Sizing and economic analysis of a solar photovoltaic micro power system for Arundel Boarding house with or without net metering.
}

\author{
Kundayi V. Mukucha, Tawanda Hove, and Tawanda Mushiri* \\ Department of Mechanical Engineering, University of Zimbabwe, P.O Box MP167 Mount \\ Pleasant, Harare, Zimbabwe \\ \{tawanda.mushiriegmail.com\}
}

\begin{abstract}
In this research, a hybrid solar photovoltaic micro power system that would improve the power supply reliability to desirable levels at the least possible cost was designed for Arundel Boarding House in Mount Pleasant experiencing drastic load shedding and yet accommodating University of Zimbabwe students. A solar powering system required to improve electricity supply reliability, was sized using a Microsoft Excel simulation model for a hybrid solar power system, designed using solar geometry and radiation relationships and also using dimensionless parameters. All the size variables where expressed as dimensionless parameters in order to generalize the system such that it would be useful to other places with the same economic conditions, solar radiation and load pattern. The program takes into account solar climatological data like solar radiation, ambient temperature and variability of the electrical load and then computes the energy, supply, reliability, LCOE as output. The reliability level was set and the combination that got the least LCOE was noted using the graphing method. Cost advantages of net metering (a billing mechanism that credits individuals who generate off-grid electricity for the electricity they add to the grid) were compared. The Excel model revealed that 5 of $\mathrm{A} / \mathrm{A}_{0}$ (dimensionless parameter for array area) required supplying power of $15.46 \mathrm{~kW}, 15.46 \mathrm{~kW}$ inverter power and $76.81 \mathrm{kWh}$ of battery capacity for a daily demand load of $74.212 \mathrm{kWh}$. In the project it was shown that with net metering the least LCOE resulted in $24.0 \mathrm{c} / \mathrm{kwh}$ whereas without resulted in $29.1 \mathrm{c} / \mathrm{kWh}$ and showed that the use of net metering can reduce significantly the cost of the power system. The Grid-tied photovoltaic powering system was found to be more cost efficient when utilizing the net metering strategy LCOE as $24 \mathrm{c} / \mathrm{kWh}$ at a reliability of $99 \%$. Hence the government should implement/legislate the net metering strategy to improve the reliability of supply of grid electricity.
\end{abstract}

Keywords: Net metering, Photovoltaic, LCOE

\section{Introduction}

\subsection{Background to the Study}

As load shedding, has become common in Zimbabwe of these shortages, residential including Arundel boarding house and commercial users of electricity have incurred costs in trying to attain reliable electricity using other reliable but costly generators of electricity. Arundel boarding house carries 70 students in capacity from University of

ACRID 2017, June 20-21, Victoria Falls, Zimbabwe

Copyright (C) 2017

DOI 10.4108/eai.20-6-2017.2270756 
Zimbabwe who require up to $18500 \mathrm{kWh}$ of energy per month .But the house experiences power cuts of up to $18 \mathrm{hrs}$ a day such that the inhabitants resort to using expensive and environmentally unfriendly diesel generators in order to compensate for their loss. A solar photovoltaic micro power system is a system that generates electricity and possibly heat, to serve a nearby load by using photovoltaic modules to convert sunlight into electricity. Photovoltaic force era utilizes sun powered boards made out of various sun based cells containing a photovoltaic material [18]. Sizing a solar photovoltaic system is determining the number and sizes of components a solar photovoltaic system for a specific demand requirement and specific purpose require in order to fully function efficiently and at the most possible minimum cost.

\subsection{Dimensionless parameters}

Use of dimensionless parameters makes it possible for the simulation developed by the researcher to be useful in sizing solar powering systems for other places in the region which receive the same solar radiation and have load shape/pattern [11]. The load shape is shown by the values of $\mathrm{L} / \mathrm{L}_{\text {day }}$ at specific hours of the day where $\mathrm{L}$ represents the load demand of the house in the specific hour and L day represents the total load demand required for the whole day ( 24 hours). $\mathrm{L} / \mathrm{L}_{\text {day }}$ (dimensionless parameter) is the ratio of the load demand of a specific hour to the daily load demand. It is possible to size a solar photovoltaic system for a different place with a different daily load but with the same load demand shape using these dimensionless parameters. $\mathrm{A} / \mathrm{A}_{0}$ is also a dimensionless parameter that indicates the solar array area by the number of solar arrays that could be summed up to make the array area.

\subsection{Economic analysis and net metering}

Economic analysis is a systematic approach that involves comparing two or more alternatives in achieving a specific objective under given assumptions and constraints, to determine the optimum use of resources that are not readily available. Net metering is a billing mechanism that credits sunlight based vitality framework proprietors for the power they add to the lattice [1]. On the off chance that the house is net-metered, the power meter will run in reverse to give a credit against what power is devoured during the evening or different periods where the home's power use surpasses the framework's yield. The electricity supply from the main grid has been so unreliable such that University of Zimbabwe students at Arundel house experience limited hours of study, increased rentals from the expense of fuel for the generator and loss of perishables. Size the solar systems in such a way as to improve the reliability of electricity to desirable levels and facilitate maximum output of power for the least cost of electricity in the boarding house. To compare the levelized cost of energy through the reliability cost method of different solar panel arrangements and consumption by using excel and select among the solar systems based on least levelized cost of energy (LCOE). To compare the solar based systems with the conventional diesel generator systems and compare cost advantages of net metering strategy against no net metering. 


\section{Materials and methods}

\subsection{System requirement sizing}

System sizing was done in order to determine the total energy consumption of the house that is the size of the power system that would be required to correspond to the power demands of the house. To achieve this the demand matrix and the appliance and time of use matrix where combined. A demand matrix which resulted in concluding the total power demand of the house was created. The researcher created another matrix for the time for which the appliances were used against the appliances mentioned. (Load profile matrix) A combination of the demand matrix and the appliance time of use matrix to resulted in a matrix which showed the total energy used by the electrical appliances per hour. The resulting graph that compares the electricity demand and electricity supply, the size of the battery required is deduced. The extent to which the load and supply are not in step defines the size of the battery required for use in the house.

\subsection{Determination of solar powering system}

The researchers developed the excel program that would suit the load shedding schedule and the meteorological conditions (temperature and solar radiation) of required location. The researcher placed load shedding grid schedule into the calculator section of the program in the column for grid so that the program would be able to identify the times of the day when the electricity supply from the main grid was $\mathrm{ON}$ and OFF. The solar radiation and ambient temperature schedule of Harare for two years 2004 to 2005 was retrieved from the solar radiation data base SoDa and placed into the appropriate columns in the excel calculator so that this data would be used in calculating PV array output power. The variation of PV efficiency with both solar irradiance and ambient temperature is then calculated for each hour through the equation in the excel calculator. The input sheet of the solar hybrid excel program includes dimensionless system parameters. These dimensionless parameters were continuously varied in order to attain certain reliability levels at the output so as to compare at these levels the lowest levelized cost of energy. System load matrix shows the discrete energy demands in each hour of the day and the total daily energy demands of the house. The matrix for economic parameters include the lifespan, capital costs, maintenance cost of the various solar components where use in the resulting solar photo voltaic system. The system simulation graph displaying the hourly variation of the electrical energy supplied by the electrical energy sources and energy drawn out from the energy suppliers in the solar hybrid powering system would be displayed in response to the input information. From the outputs of the process LCOE was used in determining the most cost optimal system. The researchers went on to replace the initial economic parameters with the cost/unit of the solar components in order to identify the actual levelized cost incurred. 


\section{Research findings and results}

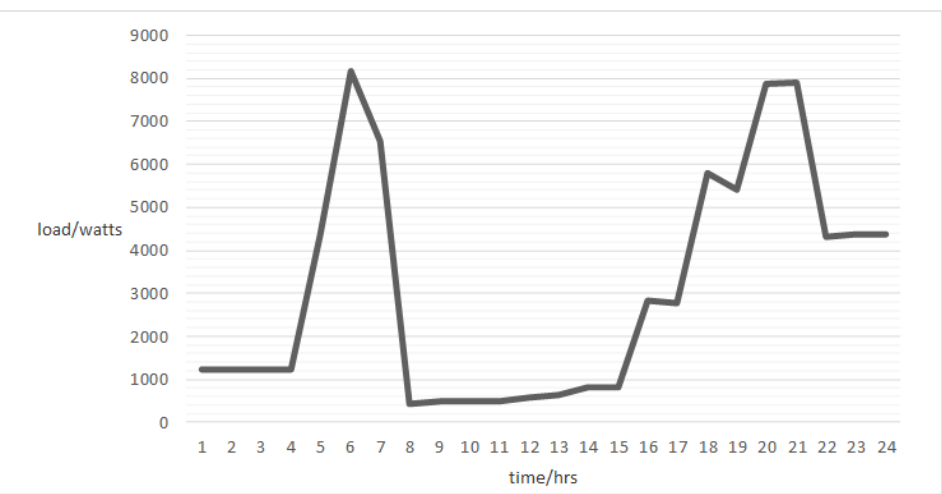

Figure 1. Load profile

From the load shedding schedule the consistency of power cuts on the house and the slots in which electrical power is actually available are shown in figure 2.

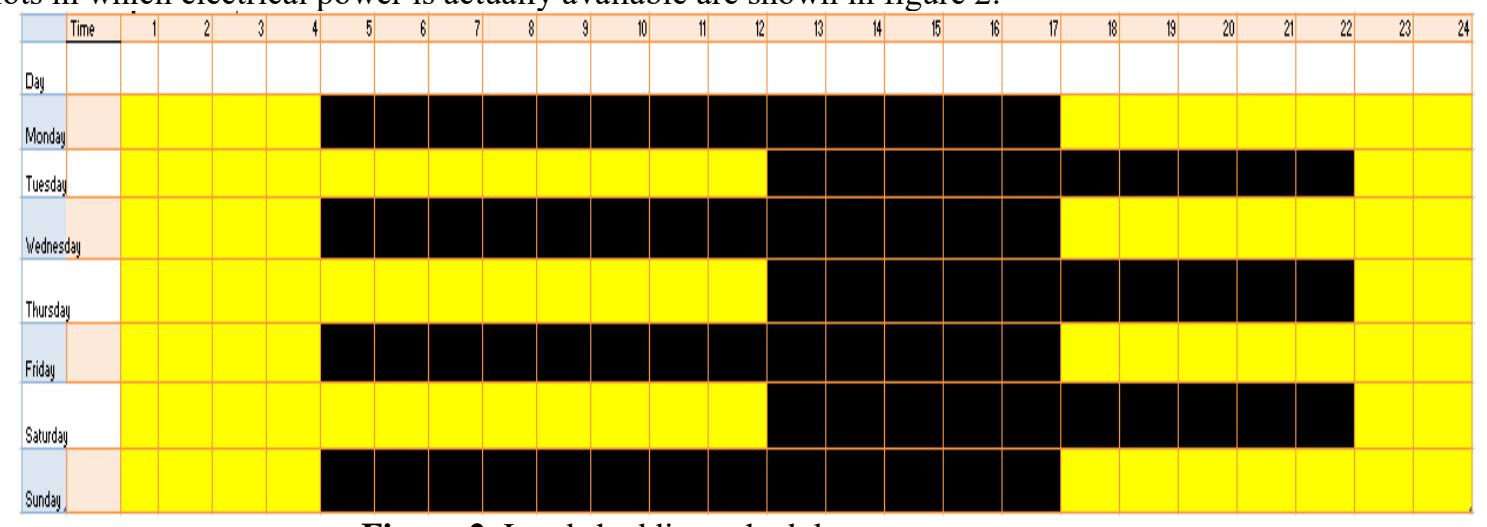

Figure 2. Load shedding schedule

The load profile shows the power demand from the house corresponding with the time it is required. The output section of the excel sheet revealed the outcome of the already existing power system used at the house in terms of daily energy demand, energy supply reliability, operating costs and levelized cost of energy. 


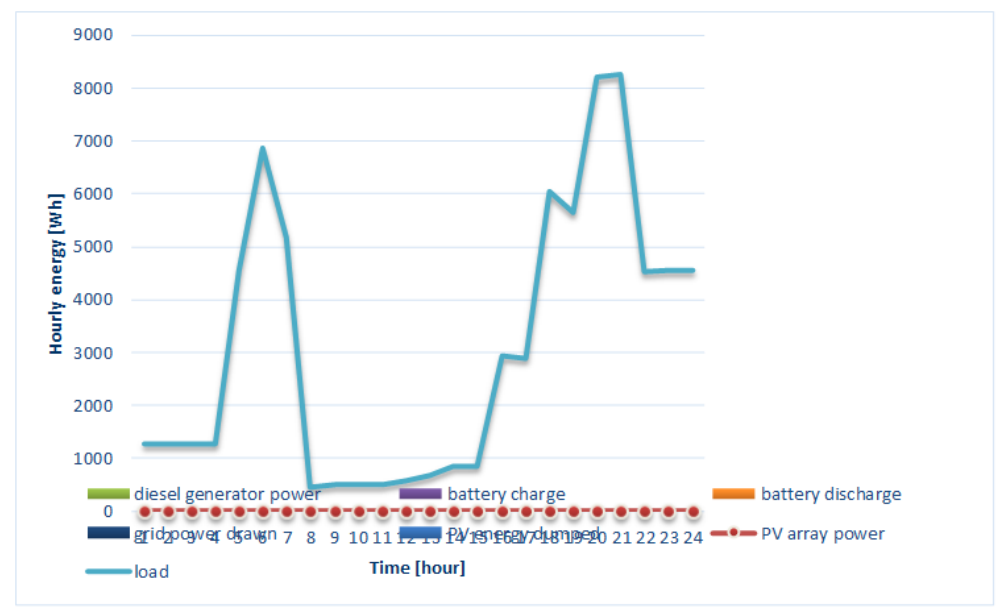

Figure 3. Trending in energy supplied to energy usages

From the figure 4, the various levelized cost of energy output against the different areas of the solar panels that could be available were compared for the three levels of reliability so as to determine the combination that would be least costly.

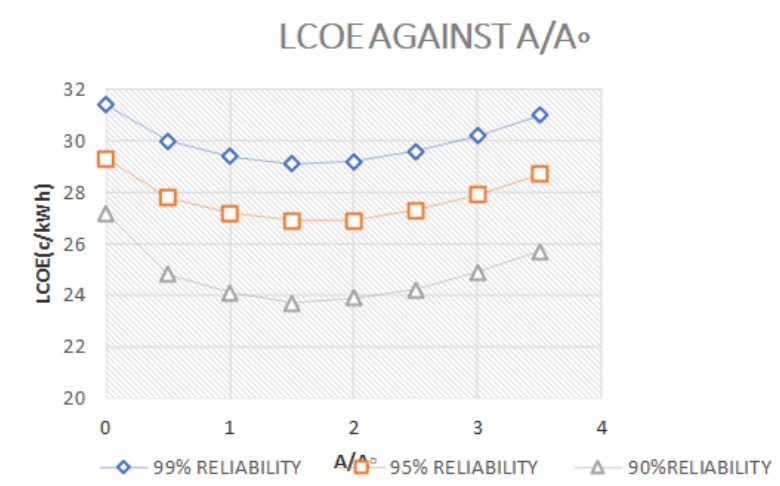

Figure 4. LCOE against array area graph for no generator and no net metering before research

For a powering system with only solar as an electricity supply but no diesel generator nor net metering the best system of this kind based on the LCOE for $99 \%$ reliability is that with $1.5 \mathrm{~A} / \mathrm{A}_{0}$ (this means $\mathrm{A}$ of 30.915 ) and a $\mathrm{B}_{\text {cap }} / \mathrm{L}_{\text {day }}$ of 1.08 (this means a battery capacity of $80.15 \mathrm{kWh}$ ). The table below shows the best systems based on the lowest LCOE of the other systems shown by the graph above.

Table 1: Properties of lowest levelized systems for the different reliabilities before research

\begin{tabular}{|l|l|l|l|}
\hline MIN & $99 \%$ & $95 \%$ & $90 \%$ \\
\hline LCOE & 29.1 & 26.9 & 23.7 \\
\hline
\end{tabular}




\begin{tabular}{|l|l|l|l|}
\hline $\mathrm{B}_{\mathrm{cap}} / \mathrm{L}_{\mathrm{day}}$ & 1.08 & 0.885 & 0.63 \\
\hline $\mathrm{A} / \mathrm{A}_{0}$ & 1.5 & 1.5 & 1.5 \\
\hline
\end{tabular}

Considering a grid connected electricity system to a solar photovoltaic system but not a diesel generator the levelized cost of electricity varies with $\mathrm{A} / \mathrm{A}_{0}$ as shown below. For a powering system with only solar as an electricity supply but no diesel generator nor net metering the best system of this kind based on the LCOE for $99 \%$ reliability is that with $1.5 \mathrm{~A} / \mathrm{A}_{0}$ (this means $\mathrm{A}$ of 30.915 ) and a $\mathrm{B}_{\text {cap }} / \mathrm{L}_{\text {day }}$ of 1.08 (this means a battery capacity of $80.15 \mathrm{kwh})$.

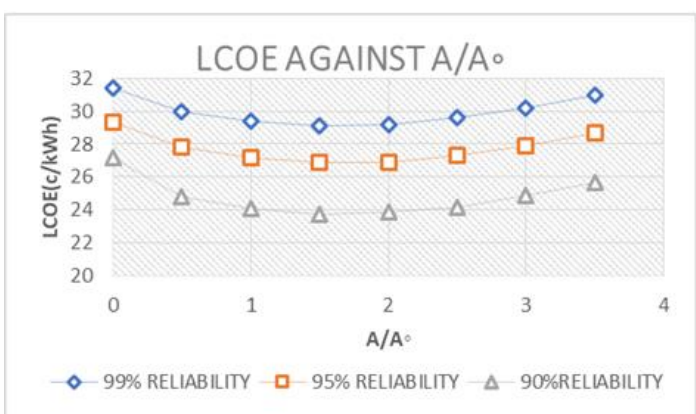

Figure 5. LCOE against $A / A_{0}$ for no generator and no net metering after research.

Table 2. LCOE against $\mathrm{A} / \mathrm{A}_{0}$ for no generator and no net metering after research.

\begin{tabular}{|l|l|l|l|}
\hline MIN & $99 \%$ & $95 \%$ & $90 \%$ \\
\hline $\mathrm{LCOE}$ & 29.1 & 26.9 & 23.7 \\
\hline $\mathrm{B}_{\text {cap }} / \mathrm{L}_{\text {day }}$ & 1.08 & 0.885 & 0.63 \\
\hline $\mathrm{A} / \mathrm{A}_{0}$ & 1.5 & 1.5 & 1.5 \\
\hline
\end{tabular}

The trend for the LCOE the same but the values for this system type are higher than the systems with no generator. The higher cost of fuel for the generator owes to the higher values of LCOE.

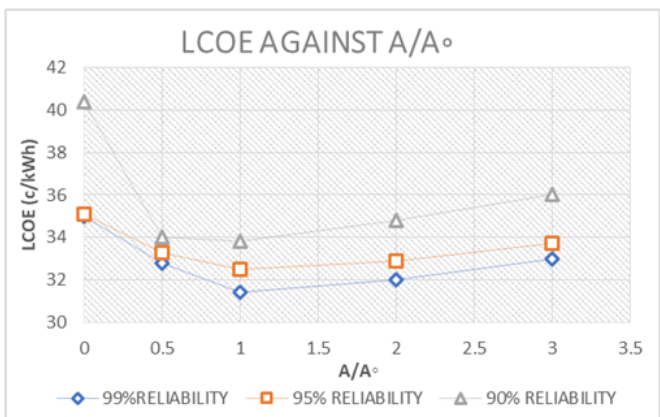

Figure 6. LCOE against $\mathrm{A} / \mathrm{A}_{0}$ for no net metering with diesel generator system 
Table 3. LCOE against $\mathrm{A} / \mathrm{A} 0$ for no net metering with diesel generator system

\begin{tabular}{|l|l|l|l|}
\hline Min & $99 \%$ & $95 \%$ & $90 \%$ \\
\hline LCOE & 24 & 21.6 & 18.8 \\
\hline $\mathrm{B}_{\text {cap }} / \mathrm{L}_{\text {day }}$ & 1.035 & 0.825 & 0.565 \\
\hline $\mathrm{A} / \mathrm{A}_{0}$ & 5 & 5 & 5 \\
\hline
\end{tabular}

The best system of this kind based on the LCOE for different levels of reliability is shown below.

Table 4. LCOE against $\mathrm{A} / \mathrm{A} 0$ for no generator with net metering

\begin{tabular}{|l|l|l|l|}
\hline Min & $99 \%$ & $95 \%$ & $90 \%$ \\
\hline $\mathrm{LCOE}$ & 24 & 21.6 & 18.8 \\
\hline $\mathrm{B}_{\mathrm{cap}} / \mathrm{L}_{\text {day }}$ & 1.035 & 0.825 & 0.565 \\
\hline $\mathrm{A} / \mathrm{A}_{0}$ & 5 & 5 & 5 \\
\hline
\end{tabular}

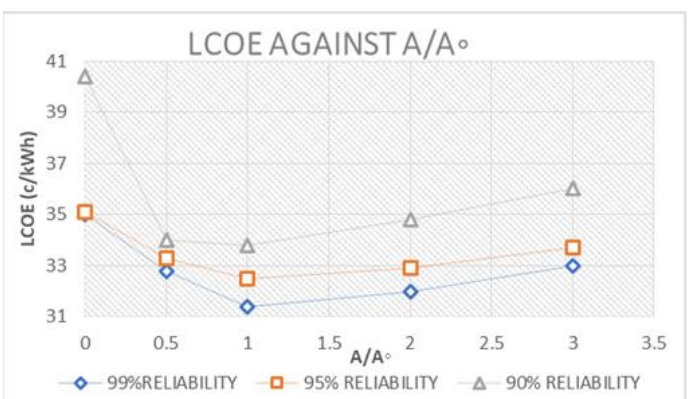

Figure 6. LCOE against $\mathrm{A} / \overline{\mathrm{A}}_{0}$ for no generator with net metering

The use of the net metering system reduces the LCOE while the use of the diesel generator which requires expensive fuel increases the LCOE as shown below.

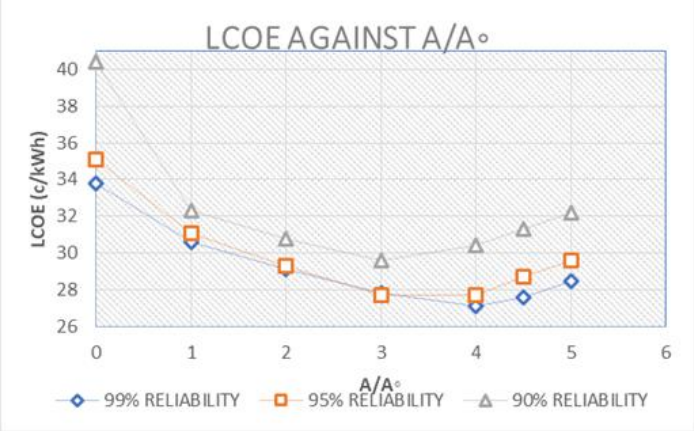

Figure 7. LCOE against $\mathrm{A} / \mathrm{A}_{0}$ for diesel generator yes and net metering yes 
Table 5. LCOE against $A / A_{0}$ for diesel generator yes and net metering yes

\begin{tabular}{|l|r|r|r|}
\hline Min & $99 \%$ & $95 \%$ & $90 \%$ \\
\hline $\mathrm{LCOE}$ & 27.1 & 27.7 & 29.6 \\
\hline $\mathrm{B}_{\text {cap }} / \mathrm{L}_{\text {day }}$ & 0.4 & 0.111 & 0.019 \\
\hline $\mathrm{A} / \mathrm{A}_{0}$ & 4 & 4 & 3 \\
\hline
\end{tabular}

\section{Discussion}

As shown by the final results of the research work, the solar hybrid system with NO generator but with net metering YES requires the least levelized cost of energy. This means that with this system the cost of buying the system equipment, installing and utilization of its energy is the least over the period of its energy consumption. Mentioned in the literature review of this project, net metering is a power approach which permits utility clients to balance a few or the greater part of their power use with self-delivered power from Renewable Energy Systems [12].This benefits the energy users by reducing their LCOE since their non-grid electricity supplying systems supply electricity back into the main grid when in excess. The graph below shows a continuous decrease in LCOE as the solar panels are increasing (this means more excess non grid electricity supply supplied back into the main grid) and thus reduced $\mathrm{LCOE}$.

Table 6. The best systems for the four electrical system combinations

\begin{tabular}{|c|c|c|c|c|}
\hline STATE OF SYSTEM & $\begin{array}{l}\text { NM YES, } \\
\text { DG YES }\end{array}$ & $\begin{array}{l}\text { NM YES, } \\
\text { DG-NO }\end{array}$ & $\begin{array}{l}\text { NM-NO, } \\
\text { DG-YES }\end{array}$ & NM-NO, DG-NO \\
\hline $\mathrm{LCOE}$ & 27.1 & 24 & 31.4 & 29.1 \\
\hline $\mathrm{B}_{\mathrm{cap}} / \mathrm{L}_{\mathrm{day}}$ & 0.4 & 1.035 & 0.442 & 1.08 \\
\hline $\mathrm{A} / \mathrm{A}_{0}$ & 4 & 5 & 1 & 1.5 \\
\hline
\end{tabular}

Key:

\begin{tabular}{|ll|l|}
\hline \multicolumn{2}{|c|}{ STATE OF SYSTEM } & ABBREVIATION \\
\hline net metering -yes diesel generator -yes & NM YES ,DG YES \\
\hline net metering-yes & diesel generator-no & NM YES,DG NO \\
\hline net metering-no & diesel generator-yes & NM NO,DG YES \\
\hline net metering-no diesel generator-no & NM-NO,DG NO \\
\hline
\end{tabular}




\section{Conclusions and Recommendations}

\subsection{Conclusions}

The solar powering system was sized using dimensionless parameters the system is fairly general for the same climatic conditions, load shape, load shedding schedule and economic parameters. In the project sizing of the solar powering system was done by considering the reliability and levelized cost of electricity such that at a required the best system would require the least levelized cost of energy.Net metering was considered to be of use in the boarding house by the sending electricity generated back to the grid. The application of net metering benefits the electricity consumer such that their electricity bills are reduced as credit for supplying individually generated electricity back to the grid. Also solar photovoltaic energy dumped is reduced and the excess electrical energy generated by the solar powering system is fully utilized .It was concluded that the photovoltaic powering system required two $8 \mathrm{kWV}$ invertor/chargers connected in series in order to convert the DC power output from the photovoltaic array to AC power and to control the current electricity supplied from the photovoltaic array.

\subsection{Recommendations}

It is recommended that a precaution against single-cell breakdown affecting other areas of the module be taken by placing solid-state diodes either in line with or across a string of cells at appropriate junctures. Dust and dirt accumulate on the surface of the solar panel during its operation such that its radiation absorption efficiency is reduced than the capacity of a clean panel such that the researcher recommends constant solar panel cleaning to maximize solar panel efficiency. This is because dirt and dust block some of the radiation from striking the actual solar panel reducing the efficiency. The maximum power output of the total PV array was less than the sum of the maximum output of the individual modules. The difference was the result of slight inconsistency in the performance of one module to the next and was called module mismatch amounting to at least $2 \%$ loss in system power. Power was also lost to resistance in the system wiring. These losses were kept to minimum. The researcher also recommends that the solar system user has a maintenance plan for panel so as to maintain the roof on which the panels are to be installed by the use of solar panel mountings [17].

\section{References}

1. Adreas, P., 2013. International journal of energy and environment. A review of net metering mechanism for electricity renewable energy systems, 4(6), pp. 975-1002.

2. Bas, L., 2010. What is an inverter/charger, California: Civicsolar. 
3. Cai, X., 2011. Effect of light intensity and temperature on the performance of GaNbased p-i-n solar cells. Yichang, IEEE, pp. 1535-1537.

4. Choruma, A., 2016. power shortages crippling economic development, Harare: Financial Gazette.

5. Darghouth, N. R., 2015. Net metering and market feedback loops Exploring the impact of both rate design on distubuted pv deployment. Carlifonia, Office of Energy Efficiency and Renewable Energy .

6. Dubey, S., 2013. Energy Procedia. Temperature Dependent Photovoltaic (PV) Efficiency and Its Effect on PV Production in the World, 7 5, pp. 311-321.

7. DUFFIE, 2006. SOLAR ENGINEERING OF THERMAL PROCESSES. NEW JERSEY: JOHN WILEY AND SONS INC.

8. Ferrey, S., 2004. Net zero. Boston, Elsevior.

9. Hove, T., 1999. Renewable Energy(21). A method for predicting long-term average, 16 December, pp. 207-229.

10. Hove, T., 2000. Renewable Energy 21(2000). A method for predicting long-term average, 16 December, pp. 207-229.

11. Martin, M., 2014. A Review of the Renewable Energy Policy and Institutional Frameworks Possible for SADC Countries. Harare, Lonworld Communications, pp. 11-16.

12. Mitcher, R., 2012. Applied Energy. Integrating rooftop solar into a multi-source energy planning optimization model, III(10), pp. 456-467.

13. P.D.C, W., 2012. Regulation for renewable energy development. Colombo, J Renene.

14. Reichel, C. H., 2015. Solar power for your home, Florida: Edison Electric Institute..

15. Robert, F., 2010. Solar Energy. 2 ed. Florida: CRC Press.

16. Steward, D., 2012. Effect of state policy suits on the development of solar markets. Colorado, National Renewable Energy Laboratory.

17. Zipp, K., 2015. Solar power world. what is the best type of battery for solar storage?, 17 December, pp. 45-47.

18. Zweibel, k., 1982. Basic photovolataic principle and methods. Solar Energy Research Institute ed. Springfield: Technical Information Offie.

19. Zweibel, P. H. a. K., 1982. Basic photovoltaic principles and methods. Colorado: Technical information office. 